\title{
A DIGNIDADE DA PESSOA HUMANA COMO VALOR-FONTE DO SISTEMA CONSTITUCIONAL BRASILEIRO
}

\section{Fernanda Schaefer Rivabem}

Graduou-se em Direito pela Pontifícia Universidade Católica do Paraná, campus Curitiba, em 2000. Especializou-se em Direito Processual Civil pela mesma instituição em 2003. Foi bolsista CAPES no Mestrado em Direito Econômico e Social da Pontifícia Universidade Católica do Paraná, curso que concluiu em março de 2005 com a defesa de dissertação: A Aplicabilidade do Código de Defesa do Consumidor aos Procedimentos Médicos Realizados à Distância, conceito A.

Autora de obras e artigos sobre responsabilidade médica e Biodireito; integrante do Grupo de Pesquisa em Biodireito, vinculado ao Mestrado em Direito Econômico e Social da PUC-PR; professora de Direito dos cursos de Ciências Contábeis e Processamento de Dados da Faculdade FACET e professora de Direito Civil (Obrigações e Contratos) do curso de Direito da Faculdade Pitágoras, ambas de Curitiba.

e-mail: fschaefer@sau.com.br ou fschaefer@terra.com.br

RESUMO: A Constituição Federal Brasileira de 1988 consagrou no art. 1ํ, inciso III, o princípio da dignidade da pessoa humana como fundamento do Estado Democrático de Direito. Diante de tal previsão constitucional restou à doutrina tentar conceituar esse importante valor fonte do sistema jurídico, político e social, buscando fixar-Ihe significado e abrangência. O presente estudo não tem a pretensão de apresentar um conceito inovador do princípio, mas demonstrar a sua relevância como valor fonte de todo sistema jurídico e social que se pretende democrático.

PALAVRAS-CHAVE: Dignidade; Pessoa humana; Constituição; Valor-fonte. 
"Nenhum princípio é mais valioso para compendiar a unidade material da Constituição que o princípio da dignidade da pessoa humana".

Paulo Bonavides (2000)

\section{INTRODUÇÃO}

A lei fundamental de um país tem por característica ser reflexo do momento histórico da sociedade que pretende regulamentar. Nesse sentido, ensina Paulo BONAVIDES (2001), que o sistema constitucional consiste em expressão que permite perceber o verdadeiro sentido tomado pela Constituição Federal em face da ambiência social que ela reflete, e cujos influxos está cada vez mais sujeita.

Assim, como a maioria das atuais Constituições Latino-Americanas, a Constituição Federal Brasileira de 1988, é fruto da luta contra o autoritarismo do regime militar, surgindo em um contexto de busca da defesa e da realização de direitos fundamentais do indivíduo e da coletividade nas mais diferentes áreas (econômica, social, política...). Seguindo a tendência do constitucionalismo contemporâneo, incorporou expressamente ao seu texto o princípio da dignidade da pessoa humana (art. 1ํㅜㄹ inciso III), definindo-o como fundamento da República e do Estado Democrático de Direito. ${ }^{2}$

Sobre a decisão do constituinte de 1988 em positivar o princípio da dignidade da pessoa humana, destaca Ingo Wolfgang SARLET (2002, p. 68)

Consagrando expressamente, no título dos princípios fundamentais, a dignidade da pessoa humana como um dos fundamentos do nosso Estado democrático (e social) de Direito (art. $1^{\circ}$, inc. III, da CF), o nosso Constituinte de 1988 - a exemplo do que ocorreu, entre outros países, na Alemanha -, além de ter tomado uma decisão fundamental a respeito do sentido, da finalidade e da justificação do exercício do poder estatal e do próprio Estado, reconheceu categoricamente que é o Estado que existe em função da pessoa, e não o contrário, já que o ser humano constitui a finalidade precípua, e não meio da atividade estatal.

\footnotetext{
${ }^{1}$ Vale aqui ressaltar que a dignidade não só é inerente ao ser humano individualmente considerado (visão ontológica) como é fruto do desenvolvimento histórico e cultural da sociedade e, por isso, deve ser considerada prévia ao Direito, existindo, portanto, independente de sua previsão expressa, cabendo ao Direito a árdua tarefa de concretizá-la (promoção e proteção).

2 Marcou a passagem de um sistema axiomático-dedutivo e extremamente positivista, para um sistema axiológico-teleológico.
} 
O constitucionalismo contemporâneo define a Constituição Federal como uma ordem objetiva de valores, ou seja, como o reflexo dos anseios da sociedade em um determinado momento histórico. Essa nova ordem permite que valores que se constroem ao longo da história da sociedade aos poucos se incorporem ao texto constitucional, preservando-o, sempre, de acordo com as necessidades sociais, políticas e jurídicas de seu tempo.

Afirma Flademir Jerônimo Belinati MARTINS (2003, p. 55)

Os valores constitucionais são a mais completa tradução dos fins que a comunidade pretende ver realizados no plano concreto - da vida real mesma - mediante a normatização empreendida pela Constituição [...] Com efeito, enquanto ordem objetiva de valores, a Constituição cumpre o importante papel de transformar os valores predominantes em uma comunidade histórica concreta em normas constitucionais; com todos os efeitos e implicações que esta normatização possa ter.

Desse entendimento do constitucionalismo contemporâneo, depreende-se a necessidade de se compreender a positivação do princípio da dignidade da pessoa humana, não só como uma conseqüência histórica e cultural, mas como valor que por si só agrega e se estende a todo e qualquer sistema constitucional, político e social e, portanto, o reconhecimento de que o ser humano passou a ser o centro de todo o ordenamento constitucional, devendo este trabalhar em prol do indivíduo e da coletividade e não o contrário.

A formulação principiológica da dignidade da pessoa humana, embora não Ihe determine um conceito fixo, atribui-Ihe a máxima relevância jurídica cuja pretensão é a de ter plena normatividade, uma vez que colocado, pelo Constituinte brasileiro, em um patamar axiológico-normativo superior e, por isso, a importância do estudo desse princípio como valor fonte, não apenas do sistema constitucional brasileiro e latino-americano, mas como fonte da hermenêutica constitucional contemporânea. 


\section{DO PRINCÍPIO CONSTITUCIONAL DA DIGNIDADE DA PESSOA HUMANA}

\subsection{Breve relato histórico}

A positivação do princípio da dignidade da pessoa humana é relativamente recente, muito embora, em civilizações remotas ${ }^{3}$ possam ser identificados dispositivos legais que já se preocupavam com a proteção do indivíduo como um fim em si mesmo.

Foi na Grécia antiga (cujo apogeu se deu no período de 600 a 300 a.C.) que começou a se desenvolver a idéia de se construir um homem com validade universal e normativa. Não há dispositivos normativos que se refiram expressamente à dignidade da pessoa humana, mas a reflexão filosófica sobre o homem foi de grande influência para o que hoje se compreende sobre a preservação dos indivíduos e da sociedade. ${ }^{4}$

Já na Idade Média, o desenvolvimento do pensamento cristão deixou como legado a elaboração das primeiras noções de dignidade da pessoa humana, tal qual se conhece hodiernamente. A idéia de igualdade inerente a todos os homens é trazida pela noção de que este é concebido à imagem e semelhança de Deus e, portanto, seria essa igualdade a expressão mais pura da dignidade da pessoa humana. Por óbvio, durante longos períodos da História da humanidade esse respeito à igualdade e à dignidade permaneceram mais no plano espiritual e subjetivo do que, propriamente, na práxis, mas esse fato não retira a importância do pensamento cristão na formação do conceito contemporâneo de dignidade da pessoa humana.

No contexto de desenvolvimento do Direito Canônico, Tomás de Aquino (1225 - 1274) foi o primeiro a se referir expressamente ao termo dignidade humana. $\mathrm{Na}$ busca de uma justificativa racional para a existência de Deus e para a fé, concebeu o homem como ser composto de matéria e espírito que formam uma unidade substancial, sobressaindo a racionalidade como caráter único do ser

${ }^{3}$ Os Códigos de Hammurabi (2394 a.C.) e Manu (200 a.C. - Índia) e a Lei das XII Tábuas (452 a.C.) traziam dispositivos que continham traços, ainda que primitivos e distantes do conceito atual, da dignidade da pessoa humana. 
humano, que o distingue dos demais seres. Assim, para Tomás de Aquino, todos os humanos são iguais em dignidade, uma vez que todos são dotados naturalmente da mesma racionalidade. Desenvolve-se, então, a noção de que a dignidade guarda estreita relação com a concepção do ser humano, como um fim em si mesmo.

Realizando um salto histórico, chega-se a Immanuel KANT (1724-1804) cuja concepção de dignidade prevalece até os dias atuais impregnada no pensamento filosófico-constitucional. O homem é concebido como sujeito do conhecimento e, por isso, é capaz de ser responsável por seus próprios atos e de ter consciência de seus deveres. Assim, mais do que respeitar um dever, tem o homem que se tornar um ser moral. Kant, então elaborou o seguinte imperativo categórico "age apenas segundo uma máxima tal que possas querer que ela se torne uma lei universal”. Desta fórmula Immanuel KANT concluiu que "o homem existe como fim em si mesmo, nunca como meio para realização das vontades”.

Mas Immanuel KANT (2003, p.76/77) não parou por aí, foi vai mais longe e afirmou que "qualquer ação é justa se for capaz de coexistir com a liberdade de todos de acordo com uma lei universal, ou se na sua máxima a liberdade de escolha de cada um puder coexistir com a liberdade de todos de acordo com uma lei universal".

Desta forma, para KANT (2003, p.70), a autonomia é uma característica fundamental e necessária do agente racional, "a autonomia é, portanto, o solo indispensável da dignidade da natureza humana ou de qualquer natureza racional", que, no entanto, só seria verdadeira, se estivesse em conformidade com o imperativo categórico da consciência moral.

A afirmação da autonomia racional é definida por KANT com a maioridade do gênero humano, isto é, a capacidade de utilização plena da razão sem a submissão a dogmas ou a autoridades, o que corresponderia ao exercício maduro da liberdade. Assim, o princípio da autonomia não seria uma questão de vontade individual, consistindo acima de tudo na máxima "que eu jamais proceda de forma que não me permita querer que minha máxima se torne uma lei geral".

Assim, raciocina o citado o filósofo, o homem é um ser único e insubstituível e todas as suas ações que instrumentalizem ou coisifiquem o homem constituem

${ }^{4}$ A maior contribuição desse período foi a racionalização do pensamento humano com a conseqüente desmistificação do homem. 
verdadeiras afrontas à dignidade humana, constituindo-se, portanto, em um ato imoral. Por isso, a importância dos estudos kantianos na formação do conceito de dignidade da pessoa humana tal qual se conhece hoje, pois só a pessoa humana, como ser único e racional, é capaz de guiar-se autonomamente por suas próprias leis. A dignidade é, desta forma, um valor intrínseco da pessoa, superior a qualquer preço que queiram lhe fixar.

Finalmente, com o término da II Guerra Mundial e a verificação das mais diversas atrocidades nela cometidas contra seres humanos, as razões históricas que levaram diversos países à constitucionalização da dignidade da pessoa humana tornaram-se evidentes e a recuperação da pluralidade do espaço público voltou a ser um ideal a ser conquistado.

No Direito comparado podem-se indicar como Constituições que atentas a esse movimento expressamente previram em seus textos o princípio da dignidade

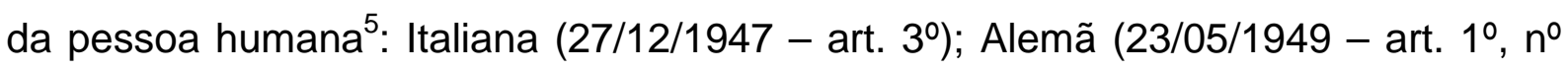
1); Portuguesa (25/04/1976 e revisão de 1989 - art. 1ํ) e Espanhola (art. 10, nํ1). ${ }^{6}$

Influenciado por esse movimento internacional (em especial, pelas três últimas leis fundamentais), o Constituinte brasileiro, de forma inédita, ${ }^{7}$ finalmente consagrou a dignidade da pessoa humana na Constituição Federal proclamada em 05 de outubro de 1988, já no Título I - Dos princípios fundamentais, art. 1º, inciso III. ${ }^{8}$

Foi em reação ao autoritarismo militar, às violações freqüentes a direitos e garantias fundamentais e ao positivismo cego que se desenvolveram os trabalhos da Constituinte de 1988 e, nesse contexto, a dignidade da pessoa humana foi constitucionalmente acolhida como fundamento da República Federativa do Brasil

5 Pelos mesmos motivos foi consagrada na Declaração Universal da ONU, em 1948, em seu art. 1ㅜㅜㅇ Declaração Americana dos Direitos e Deveres do Homem, Convenção Americana de Direitos Humanos.

${ }^{6}$ Vale noticiar que outro fato histórico também influenciou a positivação constitucional da dignidade da pessoa humana - com o fim do socialismo, diversas constituições do leste europeu também incorporaram a dignidade da pessoa humana em seus ordenamentos constitucionais. Por exemplo: Croácia (22/12/1990 - art. 25); Bulgária (12/07/1991 - preâmbulo); Eslováquia (1\%/09/1992 - art. 12) e Rússia (12/12/1993 - art.21).

7 Inédita porque embora em algumas Constituições anteriores a dignidade da pessoa humana fosse em alguns dispositivos prevista, esses dispositivos não guardavam relação com a importância e abrangência que hoje esse valor possui no ordenamento constitucional brasileiro. Veja-se, por exemplo, a Constituição Federal de 1934 (art. 115, parágrafo único); a de 1946, em seu art. 145; a de 1967 que pela primeira vez utilizou a expressão em uma formulação principiológica (art. 157, inciso II) - estrutura mantida na Emenda Constitucional de 1969 (art. 160). Disposições que se mostraram incapazes de evitar a violação da dignidade da pessoa humana, pois não possuíam mecanismos de concretização e sua interpretação era mais restrita.

8 Outros dispositivos constitucionais também prevêem expressa ou implicitamente a dignidade da pessoa humana: arts. 170; 226, §7º; 227. 
e do Estado Democrático de Direito, o que significa afirmar que ao Estado é conferida a tarefa de preservá-la, promovendo condições que a tornem possível de realização prática.

Sobre a formulação principiológica da dignidade da pessoa humana adotada pela Constituição Federal de $1988^{9}$ destaca Flademir Jerônimo Belinati MARTINS (2003, p. 50)

Quando cotejada com as Constituições anteriores não deixa de ser uma ruptura paradigmática a solução adotada pelo constituinte na formulação do princípio da dignidade da pessoa humana. A Constituição brasileira de 1988 avançou significativamente rumo à normatividade do princípio quando transformou a dignidade da pessoa humana em valor supremo da ordem jurídica [...].

Nesse sentido, também destaca Ingo Wolfgang SARLET (2001, p. 111-112)

A qualificação da dignidade da pessoa humana como princípio fundamental traduz a certeza de que 0 art. 1ํㅡㄹ inciso III, de nossa Lei Fundamental não contém apenas uma declaração de conteúdo ético e moral (que ela, em última análise, não deixa de ter), mas que constitui uma norma jurídico-positiva com status constitucional e, como tal, dotada de eficácia, transformando-se de tal sorte, para além da dimensão ética já apontada, em valor jurídico fundamental da comunidade.

Mas, por óbvio, não seria a simples previsão constitucional que faria 0 princípio ser respeitado e, principalmente, efetivado objetivamente, mas, sim, a concretização de condições que tornem possível a plenitude constitucionalmente consagrada. Nesse sentido, ensina Jesus González PEREZ (1986, p. 20-21) “todo depende de que seamos capaces de superar la esclavitud a la letra de la ley escrita y de que, partiendo de los principios, sepamos, a través de una correcta interpretación, cumplir aquellos fines".

Da compreensão de que a simples previsão constitucional não bastaria para efetivar a dignidade da pessoa humana, o Constituinte de 1988 elaborou um amplo e

9 Apenas recentemente a dogmática constitucional vem se adaptando à nova realidade trazida pela Constituição Federal de 1988. 
aberto (não-taxativo) sistema de direitos e garantias fundamentais que direta ou indiretamente buscam concretizar, na prática, esse o princípio fundamental. ${ }^{10}$

Assim, a dignidade da pessoa humana ingressou no ordenamento jurídico brasileiro como uma norma que engloba noções valorativas e principiológicas, tornando-se preceito de observação obrigatória, fundamento da República Federativa do Brasil cujo valor no ordenamento constitucional deve ser considerado superior e legitimador de toda e qualquer atuação estatal e privada, individual ou coletiva.

A proclamação constitucional do princípio da dignidade da pessoa humana é a oficialização de um direito previsto por civilizações antigas e cuja História humana mostrou ser importante constar expressamente nos ordenamentos jurídicos em conjugação com direitos e garantias fundamentais que possibilitem a sua concretização prática.

A Constituição brasileira de 1988 atribuiu plena normatividade à dignidade da pessoa humana, ${ }^{11}$ projetando-a para todo o sistema jurídico, político e social, tornando-a o alicerce principal da República e do Estado Democrático de Direito e permitindo que possua proeminência axiológica-normativa sobre os demais princípios. Conclui Cármen Lúcia Antunes Rocha, citada por Flademir Jerônimo Belinati MARTINS (2003, p. 78) que

A positivação do princípio como fundamento do Estado do Brasil quer significar, pois, que esse existe para o homem, para assegurar condições políticas, sociais, econômicas e jurídicas que permitam que ele atinja seus fins: que o seu fim é o homem, como fim em si mesmo que é, quer dizer, como sujeito de dignidade, de razão digna e supremamente posta acima de todos os bens e coisas, inclusive do próprio Estado.

Percebe-se, portanto, que a dignidade da pessoa humana deixou de ser uma mera manifestação conceitual do direito natural, para se converter em um princípio autônomo intimamente conectado à realização e concretização dos direitos

10 Destaca Flávia PIOVESAN (2003, p. 01) que "os direitos humanos nascem como direitos naturais universais, desenvolvem-se como direitos positivos particulares, para finalmente encontrarem sua plena realização como direitos positivos universais". E não foi diferente a evolução do princípio da dignidade da pessoa humana.

${ }^{11}$ O que demonstra a inversão na ordem política brasileira. O homem, em todas as suas dimensões, passa a ser a preocupação maior do Estado e prioridade justificante do Direito e qualquer afronta à dignidade pode ser caracterizada como afronta ao Estado Democrático de Direito. 
fundamentais $^{12}$ e que impõe limites à atuação estatal e particular visando a mais ampla proteção do ser humano. Trata-se de princípio que mesmo não estando expresso em todos os ordenamentos constitucionais latino-americanos, passou a ser mundialmente reconhecido como um direito humano e, portanto, inafastável de qualquer relação jurídica, econômica, social e política.

\subsection{Conceito, conteúdo e significado}

Embora seja muito fácil identificar situações em que a dignidade é desrespeitada, maior dificuldade se encontra em definir o princípio da dignidade da pessoa humana, pois, tratando-se de um princípio aberto e não taxativo, possui múltiplos significados e efeitos. Não é pretensão do presente estudo desenvolver um conceito inovador, mas delimitar alguns aspectos que devem ser considerados ao se efetivar o princípio da dignidade da pessoa humana como valor fonte de todo 0 sistema jurídico e social.

Sobre a dificuldade em se fixar um conceito do princípio da dignidade da pessoa humana, que se encontra em constante construção, desenvolvimento e aperfeiçoamento, ensina Antônio Junqueira de AZEVEDO (2002)

É preciso, pois, aprofundar o conceito de dignidade da pessoa humana. A pessoa é um bem, e a dignidade, o seu valor. O direito do século XXI não se contenta com os conceitos axiológicos formais, que podem ser usados retoricamente para qualquer tese. Mal o século XX se livrou do vazio do 'bando dos quatros' - os quatro conceitos jurídicos indeterminados: função social, ordem pública, boa-fé, interesse público - preenchendo-os, pela lei, doutrina e jurisprudência, com alguma diretriz material, surge agora, no século XXI, problema idêntico com a expressão 'dignidade da pessoa humana'.

E Flademir Jerônimo Belinati MARTINS (2003, p. 53)

A dificuldade é ainda maior quando verificamos os múltiplos significados atribuídos pela doutrina nacional ao princípio: ora como valor absoluto; ora como critério interpretativo; ora como um direito fundamental em si mesmo; ora como direito ao livre desenvolvimento da personalidade humana; ora como mera referência filosófica desprovida de maior normatividade. Na verdade, muitas vezes a doutrina adota dois ou mais destes sentidos sem, contudo, precisar qual q relação entre eles, o que pode gerar grande confusão.

\footnotetext{
12 Ressalte-se que não é tarefa dos direitos fundamentais assegurar a dignidade, mas garantir as condições para a sua plena realização.
} 
Por esses motivos, neste artigo, visou-se evidenciar a força axiológicanormativa do princípio da dignidade da pessoa humana, pois mesmo tendo sido reconhecida pela Constituição Federal brasileira como princípio fundamental, essa condição não Ihe retira o seu papel de valor fundamental de toda ordem jurídica nacional e mundial.

Embora também não seja objetivo desse estudo aprofundar a distinção entre valores, princípios e regras, algumas breves notas a esse respeito fazem-se aqui necessárias, para que se possa compreender essa dupla função da dignidade da pessoa humana no ordenamento constitucional brasileiro.

Os princípios constituem expressão dos valores fundamentais que informam o sistema jurídico conferindo harmonia e unidade ${ }^{13}$ às normas que o compõem. Se é verdade que os valores são dotados de menor normatividade que os princípios e as regras, não se pode, porém, negar que possam também ser utilizados como fontes de interpretação, ainda que de forma mediata ou reflexa, principalmente quando se procede à análise de situações concretas.

O sistema constitucional constitui instrumento de realização de valores reconhecidos pela sociedade, e esse caráter instrumental do sistema jurídico constitucional permite que valores como a dignidade da pessoa humana ganhem, ao menos indiretamente, certo grau de normatividade. Nesse sentido, Cármen Lúcia Antunes Rocha, citada por Flademir Jerônimo Belinati MARTINS (2003, p. 57) ensina que

Os princípios constitucionais são os conteúdos intelectivos dos valores superiores adotados em dada sociedade política, materializados e formalizados juridicamente para produzir uma regulação política no Estado. Aqueles valores superiores encarnam-se nos princípios que formam a própria essência do sistema constitucional, dotando-o, assim, para cumprimento de suas funções, de normatividade jurídica. A sua opção ético-social antecede a sua caracterização normativo-jurídica. Quanto mais coerência guardar a principiologia constitucional com aquela opção, mais legítimo será o sistema jurídico e melhores condições de ter efetividade jurídica e social. 
Assim os valores constitucionais possuem tríplice função: fundamento do ordenamento jurídico e informador do sistema jurídico-político; orientador dos fins a serem perseguidos na execução de atos públicos ou particulares; crítica de fatos ou condutas. Os valores constitucionais, como diretivas gerais que são, constituem o contexto axiológico fundamentador da interpretação do ordenamento jurídico e desse entendimento não se afasta o papel jurídico-constitucional atribuído à dignidade da pessoa humana, ainda que tal previsão possa ser apenas implícita ou indireta.

Já os princípios, são normas dispostas em linguagem normativa (deôntica) e que não determinam expressamente as condições que tornam sua aplicação necessária. Estabelecem um fundamento que marcam uma direção ao intérprete e conforme ensina Antonio Enrique Pérez LUÑO (1999, p.292) diference-se dos valores por apresentarem um maior grau de concreção e especificação do que estes, sendo capazes de ser fonte imediata e direta de soluções jurídicas. Os princípios, portanto, possuem grande significado hermenêutico e atuam como fontes do direito ou determinações de valor recebendo especial orientação daqueles valores que concretizam. São, portanto, vinculantes e dotados de plena juridicidade.

O princípio da dignidade da pessoa humana possui inquestionável componente axiológico-normativo e, por isso, a doutrina, de maneira geral, ao se referir a ele o faz sem distinguir se princípio ou valor ${ }^{14}$, distinção essa que também não será observada nesse trabalho. Além disso, ensina Ingo Wolfgang SARLET (2002, p.27) que "em se levando em conta que a dignidade, acima de tudo, diz com a condição humana do ser humano, cuida-se de assunto de perene relevância e atualidade, tão perene e atual for a própria existência humana”.

Portanto, o conceito jurídico de dignidade da pessoa humana é indeterminado, ou seja, o seu conteúdo e a sua extensão são incertos, embora seja

13 Paulo BONAVIDES em prefácio à obra de Ingo Wolfgnag SARLET (2002) salienta que "a unidade da Constituição, na melhor doutrina do constitucionalismo contemporâneo, só se traduz compreensivelmente quando tomada em sua imprescritível bidimensionalidade, que abrange o formal e o axiológico, a saber, forma e matéria, razão e valor. Ambos os termos conjugados assinalam, com a revolução hermenêutica, o momento definitivo da supremacia principiológica dos conteúdos constitucionais sobre os conteúdos legislativos ordinários da velha dogmática e ao mesmo tempo exprimem a ascensão da legitimidade material que põe em grau de menor importância, por carência de préstimo superior nas soluções interpretativas da Constituição, o formalismo positivista e legalista do passado, peculiar à dogmática jurídica do século XIX. Por isso mesmo, mais atento ao texto das leis que ao Direito propriamente dito". 
inegável que se trata de qualidade intrínseca e indissociável de todo e qualquer ser humano, e outro não poderia ser o entendimento. Por isso, na doutrina nacional existente sobre o assunto é importante destacar o conceito elaborado por Ingo Wolfgang SARLET (2002, p. 60), por ser ele o mais abrangente, sintetizando todo o rol de proteção estabelecido por esse princípio

A dignidade da pessoa humana corresponde à qualidade intrínseca e distintiva de cada ser humano que o faz merecedor do mesmo respeito e consideração por parte do Estado e da comunidade, implicando, neste sentido, um complexo de direitos e deveres fundamentais que assegurem a pessoa tanto contra todo e qualquer ato de cunho degradante $\mathrm{e}$ desumano, como venham a the garantir as condições existenciais mínimas para uma vida saudável, além de propiciar e promover a sua participação ativa e co-responsável nos destinos da própria existência e da vida em comunhão com os demais seres humanos.

Para deixar ainda mais claro o conceito elaborado pelo citado autor, vale aqui mencionar o que ensina Ernest Bloch, citado por Antonio Enrique PÉREZ LUÑO (1992, p.318), que destaca que a dignidade da pessoa humana possui duas dimensões que the são constitutivas: a) a negativa, que significa que a pessoa não pode ser objeto de ofensas ou humilhações; b) a positiva, que presume o pleno desenvolvimento e autodeterminação de cada pessoa.

Por ser incerto o conceito jurídico do princípio da dignidade da pessoa humana, o intérprete ${ }^{15}$ assume importante valor na sua construção como valor fonte do sistema constitucional brasileiro e reflexo da sociedade em que está inserido, uma vez que o ordenamento jurídico não concede a dignidade, pois esta é inerente ao ser humano, mas reconhece-a e compromete-se a promovê-la e protegê-la.

\footnotetext{
14 Várias são as críticas com relação à distinção entre princípios e valores, mas vale aqui transcrever o entendimento de Robert Alexy (1993) de que os princípios encontram-se no âmbito deontológico (dever-ser) e os valores são conceitos axiológicos (juízos de valor).

${ }^{15}$ Para os fins do presente trabalho considera-se intérprete todos aqueles participantes do processo de interpretação catalogados por Peter Häberle (1997, p. 13) já que a atividade interpretativa não é de exclusividade estatal. Segundo a teoria da legitimação pluralista para a interpretação pelo autor elaborada, são intérpretes: 1as funções estatais: a) na decisão vinculante (da Corte Constitucional); nos órgãos estatais com poder de decisão vinculante, submetidos, todavia, a um processo de revisão; 2- os participantes do processo de decisão nos casos antes mencionados, que não são necessariamente órgãos do Estado, isto é: a) o requerente ou recorrente e o requerido ou recorrido no recurso constitucional; b) outros participantes do processo, ou seja, aqueles que têm direito de manifestação ou integração à lide; c) pareceristas ou expertos; d) peritos e representantes de interesses nas audiências públicas do Parlamento, peritos nos Tribunais, associações, partidos políticos; e) grupos de pressão organizados; f) requerentes ou partes nos procedimentos administrativos de caráter participativo; 3- a opinião pública democrática e pluralista e o processo político como grandes estimuladores a mídia, igreja, teatros, escolas... 4- cumpre esclarecer ainda o papel da doutrina constitucional nos itens 1, 2 e 3, cujo papel é essencial por tematizar a participação de outras forças e ao mesmo tempo, participas no diversos níveis.
} 
Assim, a sua relevância como valor fonte, portanto, dá-se não somente pela sua posição topográfica no texto constitucional, mas em virtude do amplo reconhecimento de direitos e garantias fundamentais, que indiscutivelmente são a concreção histórica do princípio fundamental da dignidade da pessoa humana e sua legitimação e concretização na práxis constitucional.

Portanto, como fonte do sistema constitucional a dignidade da pessoa humana condiciona não só a atuação estatal e particular como toda a interpretação da lei fundamental, conferindo, dessa forma, unidade axiológica-normativa aos dispositivos constitucionais, mesmo aqueles que aparentemente parecem ser inconciliáveis.

\section{A DIGNIDADE DA PESSOA HUMANA COMO VALOR FONTE DO SISTEMA CONSTITUCIONAL}

No item anterior demonstrou-se que a unidade do sistema constitucional brasileiro repousa em uma ordem de valores e princípios que possui, entre o mais expressivo de todos, o da dignidade da pessoa humana e que a legitimidade substancial do Estado brasileiro se afere a partir da efetiva e concreta realização deste princípio.

\footnotetext{
Afirma Flademir Jerônimo Belinati MARTINS (2003, p. 63) que

O expresso reconhecimento da dignidade da pessoa humana como princípio fundamental traduz, em parte, a pretensão constitucional de transformá-lo em um parâmetro objetivo de harmonização dos diversos dispositivos constitucionais (e de todo sistema jurídico), obrigando o intérprete a buscar uma concordância prática entre eles, na qual o valor acolhido no princípio sem desprezar os demais valores constitucionais, seja efetivamente preservado.
}

Dessa maneira, a dignidade da pessoa humana não é o único parâmetro de interpretação e sequer pode ser considerado absoluto, mas por força de sua proeminência axiológica-normativa deve ser considerada a principal fonte da hermenêutica constitucional. Assim, para uma correta interpretação do texto é necessário que o intérprete conheça todo o sistema constitucional e a realidade histórica e cultural em que está inserido, bem como, é essencial a leitura sistemática de todo o ordenamento jurídico. 
Os princípios constitucionais fundamentais expressos ou positivados no art. 1ํ da Constituição Federal, ensina José Afonso da SILVA (1997, p. 96), devem ser considerados princípios estruturantes ou fundamentadores por expressarem decisões políticas fundamentais do Constituinte com relação à estrutura básica do Estado e as idéias e valores utilizados como parâmetros (pauta de valores ou tábua axiológica) e, por isso, não podem ser, em nenhuma hipótese, suprimidos do ordenamento (art. 60, §4으, CF) sob pena de descaracterizá-lo, levando-o à desintegração de todo o sistema constitucional.

O princípio da dignidade da pessoa humana é, portanto, um princípio fundamental do sistema constitucional brasileiro que confere racionalidade ao ordenamento jurídico e fornece ao intérprete uma pauta valorativa essencial ao correto entendimento e aplicação da norma. Trata-se, portanto, de uma valor-guia de toda a ordem jurídica, sendo que o caráter instrumental desse princípio evidencia-se na possibilidade de ser utilizado como parâmetro objetivo de aplicação, interpretação e integração de todo o sistema jurídico.

O princípio da dignidade da pessoa humana é uma cláusula aberta, de contornos ambíguos, que respalda o surgimento de novos direitos ${ }^{16}$ (não expressos, mas implícitos na Constituição Federal) e, por isso, necessita de constante concretização e delimitação pela práxis constitucional. Assim, deverá o intérprete trabalhar com a noção de que se trata de qualidade inerente a todo e qualquer ser humano, e com a perspectiva em que se reconhece a existência de uma pauta de valores constitucionais reflexos da história da sociedade, em cujo centro está, inafastável e inderrogável, a dignidade da pessoa humana.

No entanto, o correto alcance e sentido do texto constitucional só poderá ser realmente aferido se utilizada a interpretação da Constituição Federal sob uma perspectiva pluralista (noção de abertura constitucional ${ }^{17}$ de Peter Häberle). Só assim, a interpretação poderia ser considerada resultante da sociedade aberta e como elemento fundador dessa mesma sociedade, o que permite uma mediação harmoniosa entre Estado e sociedade.

Alerta Flademir Jerônimo Belinati MARTINS (2003, p. 94-95)

\footnotetext{
16 Idéia compatível com a teoria das gerações de direitos desenvolvida por Norberto Bobbio, na sua obra A Era dos Direitos.

${ }^{17}$ Noção que não se confunde com a abertura de normas constitucionais.
} 


\begin{abstract}
Não obstante, cumpre lembrar novamente que embora a dignidade da pessoa humana seja o valor fonte do sistema constitucional brasileiro não foi o único valor acolhido pelo texto constitucional. Assim, apesar de num contexto hermenêutico aberto e pluralista a concretização da dignidade da pessoa humana assumir um papel importante, senão essencial, os limites da noção de abertura constitucional não se esgotam na realização apenas desse valor [...] o que pretendemos sinalar é que a noção de abertura constitucional, para além da ampliação do círculo de intérpretes (no sentido mencionado por Peter Härbele), também implica o reconhecimento da abertura das Constituições democráticas a outros conteúdos, tanto normativos, como extranormativos (usos e convenções, normas de correção constitucional), como metanormativos (valores, postulados morais e de justiça material), o que enriquece seu sentido e alcance.
\end{abstract}

O princípio constitucional da dignidade da pessoa humana é dotado de um certo grau de vagueza e generalidade que the permite a concretização sobre inúmeras situações, quando utilizada uma enunciação normativa larga e aberta. É impregnado de profundo conteúdo ético (dimensão axiológica) e atualidade. Todas essas características Ihe permite acompanhar o ritmo frenético da evolução social presente na sociedade (bio)tecnológica, sem que com isso provoque rupturas constitucionais.

É princípio que conforma, orienta e limita criticamente a interpretação de todo o ordenamento jurídico e, por isso, funciona como operador deôntico especial, pois na medida e nas possibilidades do caso apresentado deverá orientar o intérprete. No entanto, não deve ser considerado um princípio absoluto (embora seja superior) sob o risco de se relativizar em demasia os demais princípios constitucionais, retirando-lhes a normatividade que também Ihes é inerente. $O$ valor nele contido sem dúvida alguma é absoluto, inafastável e irrenunciável, mas o princípio em si é relativo.

Vale aqui transcrever a lição de Ingo Wolfgang SARLET, sobre a relativização do princípio da dignidade da pessoa humana

Eventual relativização da dignidade na sua condição de princípio (de norma jurídica) não significa - convém reiterá-lo para evitar incompreensões - que se esteja a transigir com o caráter inviolável da dignidade considerada como qualidade inerente a todas as pessoas, que as torna sujeitos de direitos e merecedoras de igual respeito e consideração no que diz com a sua condição humana. 
Destarte, a dignidade da pessoa humana, em sua perspectiva principiológica, atua como um mandado de otimização (Robert Alexy) ordenando que seja observada e realizada na maior medida possível, considerando-se as possibilidades fáticas e jurídicas existentes no caso concreto em análise. Nesse sentido, lembra Ronald DWORKIN (1998, p. 307-309) que a dignidade da pessoa humana

Possui tanto uma voz ativa quanto uma voz passiva e, que ambas encontram-se conectadas de maneira que é no valor intrínseco da vida humana, de todo e qualquer ser humano, que encontramos a explicação para o fato de que mesmo aquele que já perdeu a consciência da própria dignidade merece tê-la considerada e respeitada".

\section{CONSIDERAÇÕES FINAIS}

A dignidade não é só um valor intrínseco do ser humano e muito menos exclusivo do ordenamento constitucional brasileiro. Na atualidade, a dignidade da pessoa humana constitui requisito essencial e inafastável da ordem jurídicoconstitucional de qualquer Estado que se pretende Democrático de Direito. Ensina Ingo Wolfgang SARLET (2002, p. 47) que

É justamente neste sentido que assume particular relevância a constatação de que a dignidade da pessoa humana é simultaneamente limite e tarefa dos poderes estatais e, no nosso sentir, da comunidade em geral, de todos e de cada um, condição dúplice ${ }^{18}$ esta que também aponta para uma paralela e conexa dimensão defensiva e prestacional da dignidade".

Ensina Joaquín Arce y FLORES-VALDÉS (1990, p. 149) que do respeito à dignidade da pessoa humana resultam quatro importantes conseqüências: a) a igualdade de direitos entre todos os indivíduos (art. 5ำ, inciso I, CF); b) a garantira da independência e autonomia do ser humano, não podendo ser utilizado como instrumento ou objeto; c) observância e proteção dos direitos inalienáveis do homem; d) não admissibilidade da negativa dos meios fundamentais para 0 desenvolvimento de alguém como pessoa ou a imposição de condições subumanas de vida (garantia de um patamar existencial mínimo). prestacional.

18 São condições dúplices da dignidade da pessoa humana, segundo o autor, a função defensiva e 
Portanto, se da observação do princípio da dignidade da pessoa humana resultam conseqüências dentro do próprio sistema constitucional, dispensável é reafirmar a importância desse valor como fonte integradora e hermenêutica de todo o ordenamento jurídico brasileiro e latino-americano e não apenas dos direitos e garantias fundamentais. ${ }^{19}$

Mesmo sendo impossível atribuir-lhe um conceito fixo e imutável, não há dúvidas que a sua aplicação em casos concretos é inafastável principalmente quando noticiados desrespeitos à vida, à integridade física e psíquica, à falta de oferecimento de condições mínimas que garantam uma existência digna, à limitação da liberdade ou a promoção da desigualdade ou, pior, nos casos em que direitos fundamentais estejam flagrantemente sendo afrontados ou desconsiderados.

A correta interpretação desse princípio leva à concretização de valores superiores, direitos e garantias fundamentais, inalienáveis e irrenunciáveis por qualquer ser humano. Pode-se, então, concluir que por se tratar de princípio ético, de inquestionável inafastabilidade, é vinculante dos poderes estatais e qualquer norma constitucional ou infraconstitucional que lhe contrarie padece de inegável ilegitimidade e deve ser afastada de plano do ordenamento jurídico.

Por fim, deve-se ressaltar que por força de sua dimensão intersubjetiva, o princípio da dignidade da pessoa humana cria um dever geral de respeito de todos os seres humanos com relação a todos os indivíduos, isolada ou coletivamente, consigo mesmo e para com os outros e por isso, afeta a todos indistintamente, intérpretes jurídicos ou não do sistema constitucional, indiferente de estar expresso ou não no ordenamento jurídico da cada país.

\section{REFERÊNCIAS}

ALEXY, R. Teoria de los derechos fundamentales. Madrid: Centro de Estudios Constitucionales, 1993.

AZEVEDO, A.J. Caracterização jurídica da dignidade da pessoa humana. Revista dos Tribunais, São Paulo, v. 91, n. 797, mar./2002, p. 11-26.

BARCELLOS, A.P. A eficácia jurídica dos princípios constitucionais: o princípio da dignidade da pessoa humana. Rio de Janeiro: Renovar, 2002.

${ }^{19}$ Nesse ponto é importante frisar que da mesma maneira que o princípio da dignidade humana serve 
BARROSO, L.R. O direito constitucional e a efetividade de suas normas: limites e possibilidades da constituição brasileira. 3. ed. atual. e amp. Rio de Janeiro: Renovar, 1996.

BONAVIDES, P. Curso de direito constitucional. 11. ed. São Paulo: Malheiros, 2001.

CANARIS, C.-W. Pensamento sistemático e conceito de sistema na ciência do direito. Lisboa: Fundação Calouste Gulbenkian, 1996.

CANOTILHO, J.J.G. Direito constitucional e teoria da constituição. 3. ed. Coimbra: Almedina, 1999.

COELHO, I.M. Interpretação constitucional. Porto Alegre: Sérgio Antonio Fabris Editor, 1997.

COSTA, C.S. A interpretação constitucional e os direitos e garantias fundamentais na constituição de 1988. Rio de Janeiro: Liber Juris, 1992.

DWORKIN, R. El dominio de la vita. Barcelona: Ariel, 1998.

ESPÍNDOLA, R.S. Conceito de princípios constitucionais. São Paulo: Revista dos Tribunais, 1999.

FELIPE, M.S.F. Razão jurídica e dignidade humana. São Paulo: Max Limonad, 1996.

FLORES-VALDÉS, J.A. Los princípios generales del derecho y su formulación constitucional Madrid: Civitas, 1990.

HÄBERLE, P. Hermenêutica constitucional. Trad. Gilmar Ferreira Mendes. Porto Alegre: Sérgio Antonio Fabris Editor, 1997.

KANT, I. A metafísica dos costumes. Trad. Edson Bini. Bauru: EDIPRO, 2003.

MARTINS, F.J.B. Dignidade da pessoa humana. Curitiba: Juruá, 2003.

MUNIZ, F.J.F; OLIVEIRA, J.L.C. O estado de direito e os direitos da personalidade. Revista dos Tribunais, São Paulo: Revista dos Tribunais, v. 532, 1980.

PASQUALINI, A. Hermenêutica e sistema jurídico - uma introdução à interpretação sistemática do direito. Porto Alegre: Livraria do Advogado, 1999.

PEREZ, J.G. La dignidad de la persona. Madrid: Civitas, 1986.

PÉREZ LUÑO, A.-E Derechos humanos, estado de derecho y constitución. 6. ed. Madrid: Tecnos, 1999.

PIOVESAN, F. Implementação das obrigações, standards e parâmetros internacionais de direitos humanos no âmbito intra-governamental e federativo. In: Painel in the Workin Session: Implementatio through instraste levels of government, including federal, state/provincial and municipal jurisdictions. Washington, USA: Inter-American Commission on Human Rights. 1ํ mar. 2003.

RABENHORST, E.R. Dignidade humana e moralidade democrática. Brasília: Brasília Jurídica, 2001.

SANTOS, F.F. Princípio constitucional da dignidade da pessoa humana. São Paulo: Celso Bastos, 1999.

como justificador dos direitos fundamentais, serve também para impor-lhes limites ou restrições. 
SARLET, I.W. A eficácia dos direitos fundamentais. Porto Alegre: Livraria do Advogado, 2001.

. Dignidade da pessoa humana e direitos fundamentais. 2. ed. rev. e amp. Porto Alegre: Livraria do Advogado, 2002.

SILVA, J.A. Curso de direito constitucional positivo. 14. ed. São Paulo: Malheiros, 1997.

A dignidade da pessoa humana como valor supremo da democracia. In: Revista de Direito Administrativo, v. 212, 1998. p. 89-94.

STRECK, L.L. Hermenêutica jurídica $e(m)$ crise - uma exploração hermenêutica da construção do direito. Porto Alegre: Livraria do Advogado, 1999.

THEODORO, M.A. Direitos fundamentais \& sua concretização. Curitiba: Juruá: 2003. 